\title{
RASAL3 preferentially stimulates GTP hydrolysis of the Rho family small GTPase Rac2
}

\author{
YOONJAE SHIN ${ }^{1}$, YONG WOO KIM ${ }^{1}$, HYEMIN KIM ${ }^{1}$, NAKYOUNG SHIN ${ }^{1}$, TAE SUNG KIM ${ }^{1}$, \\ TAEG KYU KWON ${ }^{2}$, JANG HYUN CHOI $^{3}$ and JONG-SOO CHANG ${ }^{1}$ \\ ${ }^{1}$ Department of Life Science, College of Science and Technology, Daejin University, Pocheon-Si, \\ Gyeonggi-Do 11159; ${ }^{2}$ Department of Immunology and Physiology, School of Medicine, \\ Keimyung University, Daegu 42601; ${ }^{3}$ Department of Biological Sciences, Division of Life Sciences, \\ Ulsan National Institute of Science and Technology, Ulsan 44919, South Korea
}

Received May 11, 2018; Accepted June 28, 2018

\section{DOI: $10.3892 /$ br.2018.1119}

\begin{abstract}
Members of the Ras superfamily of small G-proteins serve as molecular switches of intracellular signaling pathways. Rac2 is a Rho subfamily GTPase switch that is specifically expressed in hematopoietic cells and regulates AKT activation in cell signaling. Ras activating protein-like 3 (RASAL3) is the recently identified Ras GTPase activating protein (GAP) that is also specifically expressed in hematopoietic cells and stimulates p21ras GTPase activity. The restricted expression of both Rac2 and RASAL3 suggests that they may serve critical roles in hematopoietic cell signaling. Here in the present study demonstrates that the catalytic domain of RASAL3 may also be able to interact with Rac2 and stimulate its GTPase activity in vitro. By contrast, p50 rhoGAP molecules did not markedly affect Rac2 GTPase activity, but did accelerate the activity of other Rho GTPases, including Rac1, RhoA and Cdc42. Collectively, the present results indicate, seemingly for the first time, that GAP activity for Rac2 is regulated by the RasGAP family protein, RASAL3.
\end{abstract}

Correspondence to: Professor Jong-Soo Chang, Department of Life Science, College of Science and Technology, Daejin University, 1007 Hokuk-Ro, Pocheon-Si, Gyeonggi-Do 11159, South Korea

E-mail: jchang@daejin.ac.kr

Abbreviations: RASA1, RAS p21 protein activator 1; RASAL3, Ras activating protein-like 3; GAP, GTPase activating protein; SynGAP, synaptic GTPase activating protein; GST, glutathione $\mathrm{S}$ transferase; BCR/ABR, breakpoint cluster region/active bcr-related; ABL, Abelson murine leukemia viral oncogene homolog 1; CML, chronic myelogenous leukemia; IPTG, isopropyl $\beta$-D-1-thiogalactopyranoside; GSH, glutathione sepharose 4B

Key words: RASAL3, p50 rhoGAP, Rac2, GTP hydrolysis, GAP

\section{Introduction}

The Ras superfamily of small GTPases contains more than 170 members divided into 5 subfamilies, namely Ras, Rho, Rab, Ran and Arf (1-5). Upon ligand stimulation, the GTPases are activated by membrane-associated receptors and transmit signals to their downstream effectors, which regulate cell proliferation, differentiation, cytoskeletal regulation and vesicle trafficking $(1,3)$.

Following signal transmission, the active GTP-Ras must become inactive GDP-Ras to cease signaling. However, the intrinsic GTPase activity of Ras proteins is weak, requiring Ras GTPase activating protein (RasGAP) for efficient conversion of GTP-Ras to GDP-Ras (6). RasGAP has emerged as a novel class of tumor suppressor protein and a potential therapeutic target for cancer $(6,7)$. Therefore, it is important to identify the specific GAPs for each small GTPase. Although 14 GAPs for the Ras subfamily have previously been reported (6-10), the specific or redundant functions of these GAPs are unclear. The first RasGAP identified was p120 rasGAP, also known as RAS p21 protein activator 1 (RASA1). This protein is widely expressed, independent of cell type and tissue distribution $(11,12)$. Subsequently, neurofibromatosis type 1 was identified as a RasGAP $(13,14)$. The remaining 12 GAPs are affiliated with the GAP1 and synaptic GAP (SynGAP) family $(8,9)$. Ras activating protein-like 3 (RASAL3) is a SynGAP family member that is predominantly expressed in hematopoietic cells, including Jurkat-T cells $(15,16)$. Since RASAL3 is the most recently identified RasGAP, the specific role of this molecule in regulation of GTPase activity remains to be elucidated.

Among the Rho subfamily, which contains Rho, Rac and Cdc42 GTPases, Rac2 is specifically expressed in hematopoietic cells (17) and is known to be involved in chronic myelogenous leukemia (CML) via direct activation by the p210-breakpoint cluster region (BCR)-Abelson murine leukemia viral oncogene homolog 1 (ABL) fusion protein (18-20). Furthermore, knockout of Rac2 in mast cells resulted in defective AKT activation, followed by increased apoptosis upon agonist stimulation $(18,21)$. To date the only GAP established for Rac2 is BCR/active bcr-related (ABR) in leukemia $(22,23)$. Thus it 
appears necessary to determine the presence of Rac2 GAP in normal hematopoietic cells, since GTP-Rac2 triggers the AKT pathway in cell survival signaling $(18,20,21)$.

Although RASAL3 has been identified as a $\operatorname{RasGAP}(15,16)$, the level of GTPase activating activity in vitro was not as prominent compared to that of Rho GTPases including RhoA and Rac1. To determine the existence of a preferential target of RASAL3, the Rho subfamily of GTPases were examined. Rac2 was detected as a target GTPase for RASAL3 using an in vitro assay system. Overall it was demonstrated that RASAL3 may be a Rac2-selective GAP that has no apparent activity with Rac1. The current results may be useful to clarify the regulation mechanism of Rac2-mediated signaling at the cellular level.

\section{Materials and methods}

Reagents. Glutathione sepharose 4B (GSH) was obtained from GE Healthcare Life Sciences (Uppsala, Sweden). Reduced glutathione and isopropyl $\beta$-D-1-thiogalactopyranoside (IPTG) were purchased from Sigma-Aldrich (Merck KGaA, Darmstadt, Germany). RhoGAP Assay Biochem kit (cat. no. BK105) containing H-Ras, RhoA, Rac1 and Cdc42, separate His-Rac2 protein (cat. no. RC02) and CytoPhos Reagent were purchased from Cytoskeleton, Inc. (Denver, CO, USA). Monoclonal anti-FLAG M2 antibody (cat. no. A2220) and 3X FLAG peptide (cat. no. F4799) were purchased from Sigma-Aldrich (Merck KGaA). Pre-stained molecular weight (MW) marker was purchased from Bio-Rad Laboratories, Inc., (Hercules, CA, USA).

Vector constructs. Full-length cDNA of human RASAL3 in pFLAG-CMV/hRASAL3, constructed by Professor Masahiro Fujii (Niigata University, Niigata, Japan) (16), were used as templates for polymerase chain reaction (PCR) amplification of RasGAP domain. For glutathione $\mathrm{S}$ transferase (GST) fusion construction, amplified cDNAs encoding the RasGAP domain of RASAL3 (amino acids 421-748) were ligated into the EcoRI/XhoI (Takara Bio, Inc., Otsu, Japan) restriction sites of pGEX-5X-1. For PCR amplification, the primers 5'-ACA GAA TTC GCG CGT CGC CTG CGC GTG-3' (forward) and 5'-ACA CTC GAG TCA CAT TGG CAC TGA CAC AAG-3' (reverse) were used for the RASAL3 GAP domain (underlined sequences represent the EcoRI and XhoI digestion sites, respectively). PCR amplification was performed using a PCR amplification kit (Takara Bio, Inc.; cat. no. R011) and involved an initial step of denaturation $\left(94^{\circ} \mathrm{C}\right.$ for $\left.5 \mathrm{~min}\right)$, followed by 35 cycles of denaturation $\left(94^{\circ} \mathrm{C}\right.$ for $\left.30 \mathrm{sec}\right)$, annealing $\left(57^{\circ} \mathrm{C}\right.$ for $30 \mathrm{sec})$ and extension $\left(72^{\circ} \mathrm{C}\right.$ for $\left.30 \mathrm{sec}\right)$. Final extension was performed at $72^{\circ} \mathrm{C}$ for $10 \mathrm{~min}$.

Protein expression and purification. GST-RASAL3-GAP fusion proteins were expressed in Escherichia coli (E. coli) DH5 $\alpha$ (Takara Bio, Inc.). Protein expression was induced with $200 \mu \mathrm{M}$ IPTG overnight at room temperature $\left(\sim 18^{\circ} \mathrm{C}\right)$. Ultrasonic-disrupted cell lysates were centrifuged at $12,000 \mathrm{x} \mathrm{g}$ and $4^{\circ} \mathrm{C}$ for $20 \mathrm{~min}$, and the supernatants were incubated with GSH beads to collect GST-fused proteins in Tris-Cl buffer (50 mM Tris, pH 7.5, $150 \mathrm{mM} \mathrm{NaCl}, 1 \mathrm{mM}$ dithiothreitol, $2 \mathrm{mM} \beta$-mercaptoethanol). Fusion protein-bound beads were washed with the same Tris- $\mathrm{Cl}$ buffer, and the fusion proteins were eluted with $30 \mathrm{mM}$ reduced glutathione solution in Tris- $\mathrm{Cl}$ buffer ( $\mathrm{pH}$ 7.5). The purified proteins were concentrated using Amicon Ultra centrifugal filters (Merck KGaA, Darmstadt, Germany) at $4^{\circ} \mathrm{C}$. The resulting proteins were used for further experiments or immediately frozen in liquid nitrogen and stored at $-70^{\circ} \mathrm{C}$. The purified GAP domain protein of p50 RhoGAP (also known as Cdc42 GAP) was supplied with the RhoGAP assay kit.

FLAG-tagged RASAL3 proteins were purified from the lysates of HEK-293 cells (American Type Culture Collection, Manassas, VA, USA) that had been transiently transfected with the pFLAG-CMV/hRASAL3 vector. Transfection was performed according to the manufacturer's specification of a Lipofectamine 3000 transfection kit (Invitrogen; Thermo Fisher Scientific, Inc., Waltham, MA, USA). Following lysate centrifugation at $12,000 \mathrm{x} \mathrm{g}$ and $4^{\circ} \mathrm{C}$ for $20 \mathrm{~min}$, anti-FLAG M2 affinity gel (Sigma-Aldrich; Merck KGaA) was added to the supernatant and further incubated on a shaker at $4^{\circ} \mathrm{C}$ for $3 \mathrm{~h}$. FLAG-RASAL3 was eluted by incubating the beads at $4^{\circ} \mathrm{C}$ for $30 \mathrm{~min}$ with $200 \mathrm{ng} / \mathrm{ml}$ 3X FLAG peptide in Tris-buffered saline (pH 7.4).

In vitro binding assay. Purified His-Rac2 protein $(2 \mu \mathrm{g})$ was mixed with $50 \mu \mathrm{l} 1 \mathrm{X}$ GAP assay reaction buffer (Cytoskeleton, Inc.) in the presence of $50 \mu \mathrm{M}$ GDP, GTP or GTP $\gamma \mathrm{S}$ (Sigma-Aldrich; Merck KGaA) at $30^{\circ} \mathrm{C}$ for $10 \mathrm{~min}$. A $50 \mu 1$ slurry of beads bound to GST-RASAL3-GAP fusion protein was added to each guanosine nucleotide-charged Rac2 GTPase aliquot. Each $100 \mu \mathrm{l}$ reaction mixture was incubated at room temperature $\left(\sim 18^{\circ} \mathrm{C}\right)$ for 30 min with gentle shaking. The beads were washed with an equal volume $(100 \mu \mathrm{l})$ of $1 \mathrm{X}$ reaction buffer 3 times to remove unbound proteins. The bound proteins were resolved on an 8-16\% gradient SDS-PAGE and visualized by Coomassie Brilliant Blue staining performed at room temperature for $1 \mathrm{~h}$. Additionally, in vitro binding assays were performed between the GAP domain of RASAL3 and various small G-proteins (H-Ras, RhoA, Rac1, Rac2 and $\mathrm{Cdc} 42)$. In this case, $1 \mathrm{X}$ reaction buffer was replaced by $50 \mathrm{mM}$ Tris- $\mathrm{Cl}$ (pH 7.5) containing $150 \mathrm{mM} \mathrm{NaCl}$ and $20 \mu \mathrm{M}$ GTP. The bound proteins were washed with the same buffer and resolved on SDS-PAGE. The quantities of GTPase pulled down with GST-RASAL3 GAP domain were analyzed by relative image density (Quantity One software ver. 4.6.9; Bio-Rad Laboratories, Inc.)

GAP activity assay. GAP activity assays were performed using the RhoGAP Assay Biochem kit, which contains GST-Rho-GAP fusion protein. Briefly, GTPase activity was measured by monitoring the free $\gamma \mathrm{Pi}$ release with or without purified GAP molecules via absorbance at $650 \mathrm{~nm}$. Single turnover GTPase reactions ( $30 \mu \mathrm{l}$ total volume per reaction) were initiated by the addition of $200 \mu \mathrm{M}$ GTP. The reactions were performed at $37^{\circ} \mathrm{C}$ for $15 \mathrm{~min}$. Subsequently, $150 \mu \mathrm{l} \mathrm{CytoPhos}$ reagent was added to the reactions and incubated for a further $10 \mathrm{~min}$ at room temperature. The absorbance of the reactions was measured at $650 \mathrm{~nm}$. The reaction time was controlled to 5,10 or $15 \mathrm{~min}$ according to manufacturer's recommendations. Using each GTPase as a control, absorbance value was measured in the presence of GST alone. 
Western immunoblotting. Purified FLAG-RASAL3 solution from pFLAG-CMV/hRASAL3 transfected HEK-293 cell lysates (minimal volume $10 \mu \mathrm{l}$ ) was resolved on $10 \%$ SDS-PAGE, and transferred to nitrocellulose membrane for $4 \mathrm{~h}$ at $200 \mathrm{~mA}$ current. The blot was blocked with $5 \%$ non-fat skim milk for $1 \mathrm{~h}$ at room temperature, and probed with monoclonal anti-FLAG M2 antibody (1,000x dilution in 5\% skimmed milk) for $2 \mathrm{~h}$ at room temperature. Following extensive washing with Tris-buffered Tween-20 (50 mM Tris-Cl, $150 \mathrm{mM} \mathrm{NaCl}$, $0.5 \%$ Tween-20, $\mathrm{pH} 7.5$ ), the membrane was re-probed with hoarse-radish peroxidase conjugated goat anti-mouse IgG antibody (Jackson ImmunoResearch Laboratories, Inc., West Grove, PA, USA) for $1 \mathrm{~h}$ at room temperature and visualized with an enhanced chemiluminescence detection system (GE Healthcare Life Sciences, Little Chalfont, UK).

Statistical analysis. Experimental data are presented as the mean \pm standard deviation and were analyzed by one-way analysis of variance and Student-Newman-Keuls post-hoc testing with SPSS 22.0 software (IBM Corp., Armonk, NY, USA). $\mathrm{P}<0.05$ was considered to indicate statistical significance.

\section{Results and Discussion}

Preparation of RASAL3 GAP proteins. RASAL3 includes pleckstrin homology and $\mathrm{C} 2$ domains close to its N-termini, while its GAP domain is located in the central portion of the molecule (Fig. 1A) (7). GST-RASAL3-GAP (421-748 aa) fusion protein expressed in E. coli were purified and resolved by $10 \%$ SDS-PAGE. In a typical induction system at $37^{\circ} \mathrm{C}$, the proteins were almost pelleted by centrifugation despite the fusion protein being efficiently induced in E. coli by $200 \mu \mathrm{M}$ IPTG. The method was then modified as described in the 'Materials and methods'. A 64 kDa GST-RASAL3-GAP fusion protein was efficiently harvested by the modified methods (Fig. 1B).

GST-RASAL3 stimulates Rac2 GTPase in vitro. Recently, our group identified that a synthesized chemical directly bound to RASAL3 in Jurkat T-cell lysates (data to be published). During examination of RASAL3 GAP activity with chemical regulators, it was noted that the bacterially expressed GAP domain of RASAL3 reproducibly accelerated Rac2 GTPase activity (Fig. 2A).

Subsequently GST-RASAL3-GAP activity with $H$-Ras and Rho GTPases was examined. As depicted in Fig. 2A, RASAL3 did not markedly stimulate RhoA, Rac1 or Cdc2 GTPase activity, while it notably increased Rac2 GTPase activity. Therefore, RASAL3 was taken to preferentially stimulate Rac2, a Rho family GTPase, but not other Rho family GTPases. Although two recent reports demonstrated that RASAL3 stimulates p21ras GTPase activity $(15,16)$, the present results indicated, seemingly for the first time, that RASAL3 preferentially stimulates GTP hydrolysis in Rac2. Using each GTPase as controls, the measured absorbance value did not change in the presence of GST alone (data not shown).

In the current assay system, RASAL3 increased H-Ras GAP activity $\sim 2$-fold, while it accelerated Rac2 GTPase activity $>3.5$-fold compared with Rac2 GTPase activity

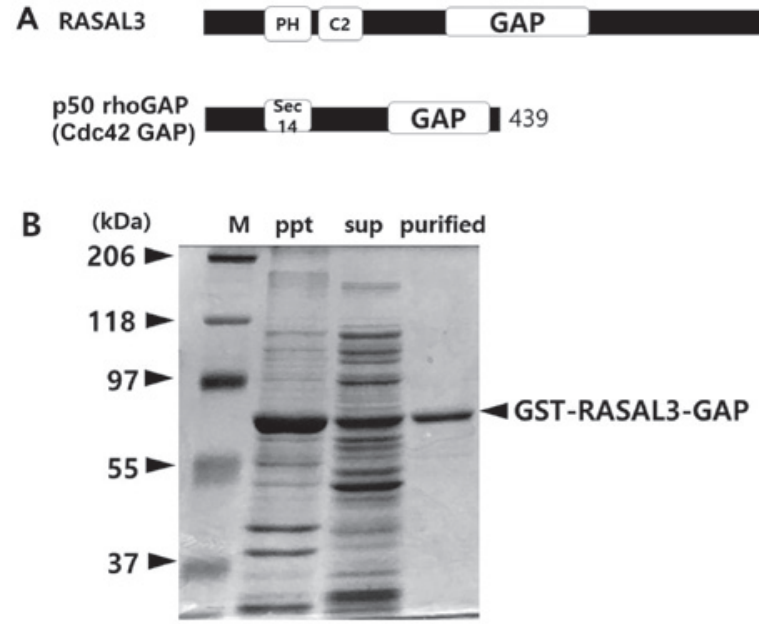

Figure 1. (A) Illustration of RASAL3 GAP molecule used in the experiments. The cDNA encoding RASAL3 GAP domain was amplified by polymerase chain reaction and fused with the EcoRI/XhoI sites of pGEX $5 \mathrm{X}-1$. The resulting recombinant DNA was transformed into $E$. coli. The p50 rhoGAP (Cdc42 GAP) protein was supplied with the RhoGAP assay kit. (B) Bacterially expressed GST-RASAL3-GAP domain fusion proteins were induced with $200 \mu \mathrm{M}$ IPTG and purified using a GSH slurry. Following treatment with reduced glutathione, GST-GAP fusion proteins were efficiently eluted, as apparent in the 'purified' lane, and visualized by Coomassie Blue staining. RASAL3, Ras activating protein-like 3; GAP, GTPase activating protein; E. coli, Escherichia coli; GST, glutathione S transferase; IPTG, isopropyl $\beta$-D-1-thiogalactopyranoside; GSH, glutathione sepharose 4B.

without RASAL3. This result suggests that RASAL3 may be a pivotal regulator of AKT-mediated signaling via Rac2 GTPase regulation in hematopoietic cells.

The GAP domains of RasGAP and RhoGAP are structurally related (24), and their GTPase tertiary folding patterns appear to be similar $(6,25)$. In particular, an arginine residue at position 789 in RASA1 or position 305 in p50 rhoGAP is reportedly capable of penetrating into the active site of each corresponding GTPase $(25,26)$. However, the current results suggested that RasGAP (RASAL3) may stimulate GTP hydrolysis of Rac2, while RhoGAP (p50 rhoGAP) did not exhibit any GAP activity with $\mathrm{H}$-Ras. Therefore, it is conceivable that Ras and Rac2 have structural similarities in their active site. Although Rac1 and Rac2 exhibit $>92 \%$ amino acid sequence homology (27), RASAL3 activated Rac2 but not Rac1, suggesting somewhat different active site structures.

The p50 rhoGAP GAP domain exhibited highest GAP activity for RhoA and $\mathrm{Cdc} 42$, while it exhibited no activity for H-Ras (Fig. 2B). The p50 rhoGAP domain increased Rac2 GTPase activation by <2-fold, while GTPase activation of RhoA, Rac1 and CDC42 increased 4-, 3.5- and 3-fold, respectively. These results suggest that $\mathrm{p} 50$ rhoGAP stimulates GTPase activity of only the Rho family small G-proteins. Furthermore, it is consistent with the report that human p50 rhoGAP has in vitro specificity only for $\mathrm{Cdc} 42$, Rac1 and RhoA (5).

Complete RASAL3 exhibits a similar activity to the GST-GAP domain. To clarify any difference in GAP activities between the GAP domain alone and the intact GAP molecule, intact RASAL3 was expressed and purified from HEK-293 cells using the pFLAG-CMV/hRASAL3 vector (16). The 


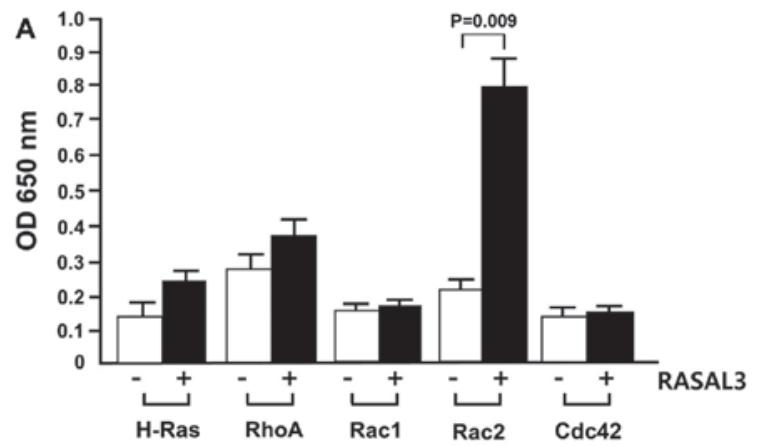

B

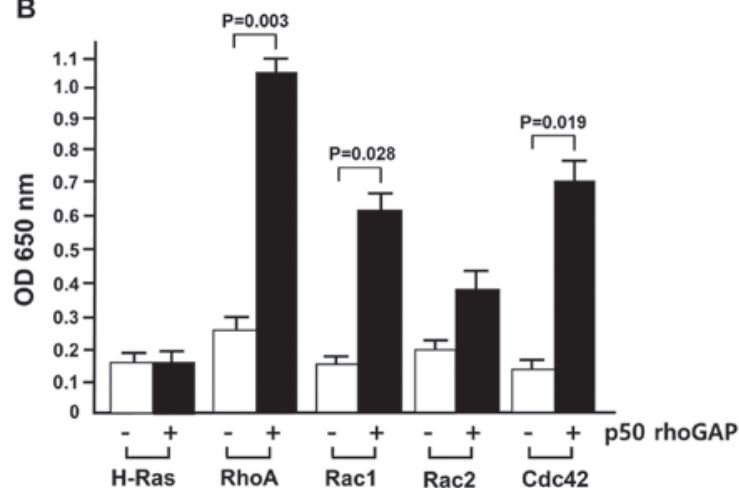

Figure 2. Comparisons of GAP activity between small G-proteins. GTP hydrolysis was determined by measuring the amount of released $\gamma \mathrm{Pi}$. Following reaction, the $\gamma \mathrm{Pi}$ level was measured in the presence of CytoPhos reagent from absorbance at $650 \mathrm{~nm}$. Hydrolysis of GTP by the indicated small G-proteins was performed either in the presence or absence of (A) GST-RASAL3 and (B) GST-p50 rhoGAP at $37^{\circ} \mathrm{C}$ for $15 \mathrm{~min}$. The CytoPhos reagent was added to the reactions and incubated for a further $10 \mathrm{~min}$ at room temperature, after which the absorbance at $650 \mathrm{~nm}$ was measured. Means \pm standard deviation of three independent experiments are represented. GAP, GTPase activating protein; GST, glutathione S transferase; RASAL3, Ras activating protein-like 3 .

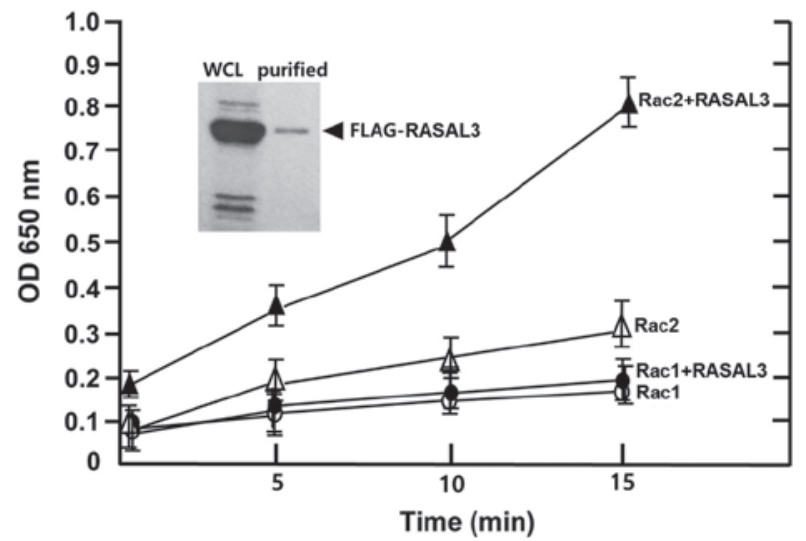

Figure 3. GAP assay using full-length RASAL3 protein. The GTPase activating activity of Rac1 and Rac2 was examined in the presence or absence of whole RASAL3 protein, which was prepared using the pFLAG-CMV/hRASAL3 vector. Means \pm standard deviation of three independent experiments are represented. The panel within the graph represents an image of western immunoblotting with anti-FLAG antibody (MW was determined as $120 \mathrm{kDa}$ ). RASAL3, Ras activating protein-like 3; GAP, GTPase activating protein; MW, molecular weight; WCL, whole cell lysate.

GTPase activity of Rac1 and Rac2 was measured in the presence and absence of FLAG-RASAL3 at certain time intervals. As depicted in Fig. 3, Rac1 GTPase activity did

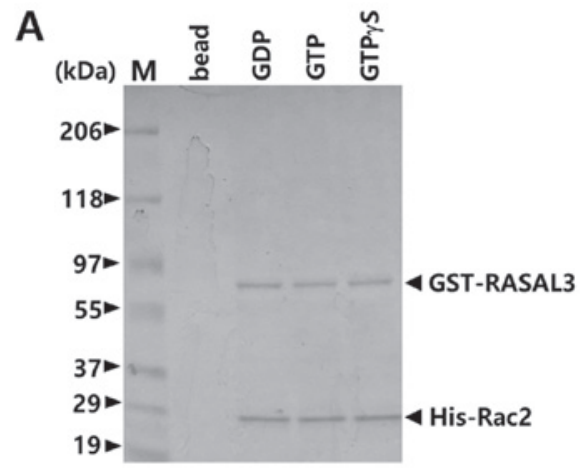

B
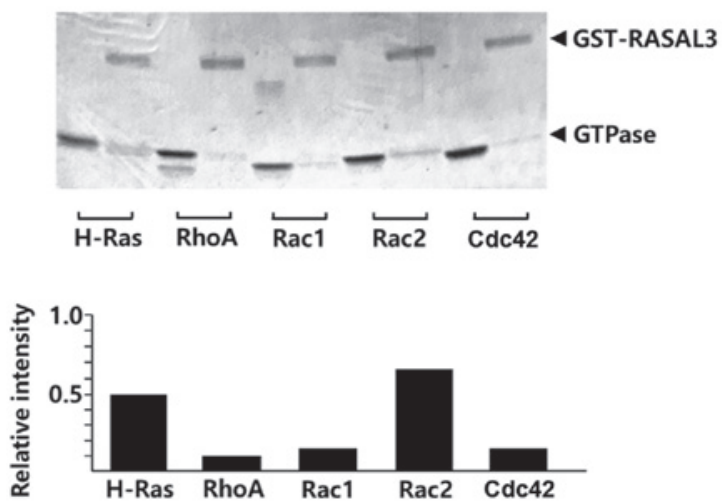

Figure 4. In vitro binding assay between RASAL3 GAP domain and Rac2. (A) Purified His-Rac2 proteins ( $2 \mu \mathrm{g}$ each) and slurries of GST-RASAL3-GAP beads $(50 \mu 1)$ were mixed with $50 \mu 1 \mathrm{lX}$ GAP assay reaction buffer in the presence of $20 \mu \mathrm{M}$ GDP, GTP or GTP $\gamma \mathrm{S}$ at room temperature for $30 \mathrm{~min}$. The bound proteins were washed and resolved on SDS-PAGE and stained with Coomassie Blue. (B) In vitro bindings between the GST-RASAL3-GAP and each small G-protein were independently performed with $50 \mathrm{mM}$ Tris-Cl (pH 7.5) containing $150 \mathrm{mM} \mathrm{NaCl}$ and $20 \mu \mathrm{M}$ GTP at room temperature for 30 min (upper). The quantities of GTPase pulled down with GST-RASAL3 GAP domain were expressed by relative image density, which was normalized against each GTPase alone (lower). RASAL3, Ras activating protein-like 3; GAP, GTPase activating protein; GST, glutathione S transferase.

not increase in the presence of FLAG-RASAL3, while Rac2 GTPase activity was markedly accelerated in the presence of FLAG-RASAL3. The stimulation rate was similar to that of GST-RASAL3-GAP (Fig. 2A), suggesting that both the FLAG-RASAL3 and GST-RASAL3-GAP domain have similar activating activity in vitro. The absorbance increased several-fold ( 3.5 -fold after $15 \mathrm{~min})$ in a time-dependent manner in the presence of FLAG-RASAL3. This contrasts the results of Rac1, which exhibited only basal level changes even in the presence of FLAG-RASAL3 (Fig. 3). Therefore, specific GTP hydrolysis of Rac2 in hematopoietic cells may be potently stimulated by RASAL3.

Rac2 interacts with GST-RASAL3-GAP. To investigate whether the GAP domains of RASAL3 interact with Rac2, an in vitro binding assay was performed with GST-GAP fusion proteins. In GST pull-down experiments, Rac2 directly associated with GST-RASAL3-GAP (Fig. 4A). GST-RASAL3-GAP did not exhibitany difference in affinity to eitherGDP-Rac2orGTP-Rac2. Generally, GTP-loaded small G-proteins exhibit higher affinity to GAP domains than GDP-loaded proteins (1). In this context, the current results may suggest that the preloaded GTP was 
efficiently degraded to GDP during binding in the presence of GST-GAP molecules at high concentration $(50 \mu \mathrm{l})$. Therefore, the Rac2 fractions pulled down with GST-RASAL3-GAP were likely Rac2 alone or GDP-Rac2. In addition, it was examined whether the GAP domain of RASAL3 binds to other G-proteins including H-Ras, RhoA, Racl and $\mathrm{Cdc} 42$ in the presence of $20 \mu \mathrm{M}$ GTP. As presented in Fig. 4B, the Rac2 band exhibited the strongest intensity among the G-proteins pulled down with GST-RASAL3-GAP. Rac2 exhibited marginally higher affinity than H-Ras for the GST-RASAL3 GAP domain, while other Rho subfamily GTPases exhibited seemingly basal level affinities. This result is consistent with the result of Fig. 2A, which overall suggests that the RASAL3 GAP domain preferentially stimulates Rac2 GTPase activity.

In conclusion, in the present study, it was suggested that RASAL3 may be responsible at least in part for controlling AKT-mediated survival signaling in hematopoietic cells via Rac2 GTPase regulation. Although results were obtained in vitro, the current findings may provide insight into the regulation mechanism of Rac2-AKT signaling at the cellular level, since the only GAP for Rac2 identified to date is BCR/ABR in Philadelphia chromosome-positive leukemia $(22,23)$. Patients with CML have lymphocytes containing the Philadelphia chromosome, caused by gene fusion between BCR and ABL. Rac GTPase in such lymphocytes has been revealed to be the fully activated form (GTP-Rac) compared with in normal lymphocytes (GDP-Rac) (28). Furthermore, it was demonstrated that CML phenotype was significantly attenuated by depletion of Rac2 in a mouse model (28), suggesting that Rac2 is a crucial regulator in CML disease. In this sense, it is conceivable that RASAL3, as a Rac2 inactivating protein, may be a possible target for CML disease.

\section{Acknowledgements}

The authors are grateful to Professor Masahiro Fujii (Niigata University, Niigata, Japan) for providing the pFLAG-CMV/hRASAL3 construct.

\section{Funding}

No funding was received.

\section{Availability of data and materials}

The analyzed data sets obtained during the study are available from the corresponding author on reasonable request.

\section{Authors' contributions}

YS and YWK analyzed GAP activity. HK, NS and TSK purified GST fusion protein. JHC purified FLAG-RASAL3 proteins from HEK-293 cells. TKK and JSC were primarily responsible for writing of the manuscript. JSC contributed to overall design, acquisition and interpretation of data. All authors approved the manuscript submission.

\section{Ethics approval and consent to participate}

Not applicable.

\section{Patient consent for publication}

Not applicable.

\section{Competing interests}

The authors declare that they have no competing interests.

\section{References}

1. Colicelli J: Human RAS superfamily proteins and related GTPases. Sci STKE 2004 (re13): RE13, 2004.

2. Csépányi-Kömi R, Sáfár D, Grósz V, Tarján ZL and Ligeti E: In silico tissue-distribution of human Rho family GTPase activating proteins. Small GTPases 4: 90-101, 2013.

3. Moon SY and Zheng Y: Rho GTPase-activating proteins in cell regulation. Trends Cell Biol 13: 13-22, 2003.

4. Reiner D and Lundquist EA: Small GTPases. WomBook May 24 2016 (Epub ahead of print).

5. Tcherkezian J and Lamarche-Vane N: Current knowledge of the large RhoGAP family of proteins. Biol Cell 99: 67-86, 2007.

6. Bos JL, Rehmann H and Wittinghofer A: GEFs and GAPs: Critical elements in the control of small G proteins. Cell 129: 865-877, 2007.

7. Maertens $\mathrm{O}$ and Cichowski $\mathrm{K}$ : An expanding role for RAS GTPase activating proteins (RAS GAPs) in cancer. Adv Biol Regul 55: 1-14, 2014.

8. Bernards A: GAPs galore! A survey of putative Ras superfamily GTPase activating proteins in man and Drosophila. Biochim Biophys Acta 1603: 47-82, 2003.

9. King PD, Lubeck BA and Lapinski PE: Nonredundant functions for Ras GTPase-activating proteins in tissue homeostasis. Sci Signal 6 (re1): re1, 2013.

10. Lubeck BA, Lapinski PE, Oliver JA, Ksionda O, Parada LF, Zhu Y, Maillard I, Chiang M, Roose J and King PD: Cutting edge: Codeletion of the Ras GTPase-activating proteins (RasGAPs) neurofibromin 1 and p120 RasGAP in lymphoblastic leukemia. J Immunol 195: 31-35, 2015.

11. Vogel US, Dixon RA, Schaber MD, Diehl RE, Marshall MS, Scolnick EM, Sigal IS and Gibbs JB: Cloning of bovine GAP and its interaction with oncogenic ras p21. Nature 335: 90-93, 1988.

12. Trahey M, Wong G, Halenbeck R, Rubinfeld B, Martin GA, Ladner M, Long CM, Crosier WJ, Watt K, Koths K, et al: Molecular cloning of two types of GAP complementary DNA from human placenta. Science 242: 1697-1700, 1988.

13. Ballester R, Marchuk D, Boguski M, Saulino A, Letcher R, Wigler $\mathrm{M}$ and Collins F: The NF1 locus encodes a protein functionally related to mammalian GAP and yeast IRA proteins. Cell 63: 851-859, 1990.

14. Marchuk DA, Saulino AM, Tavakkol R, Swaroop M, Wallace MR, Andersen LB, Mitchell AL, Gutmann DH, Boguski M and Collins FS: cDNA cloning of the type 1 neurofibromatosis gene: Complete sequence of the NF1 gene product. Genomics 11: 931-940, 1991.

15. Muro R, Nitta T, Okada T, Ideta H, Tsubata T and Suzuki H: The Ras GTPase-activating protein Rasal3 supports survival of naive T cells. PLoS One 10: e0119898, 2015.

16. Saito S, Kawamura T, Higuchi M, Kobayashi T, Yoshita-Takahashi M, Yamazaki M, Abe M, Sakimura K, Kanda Y, Kawamura H, et al: RASAL3, a novel hematopoietic RasGAP protein, regulates the number and functions of NKT cells. Eur J Immunol 45: 1512-1523, 2015.

17. Reibel L, Dorseuil O, Stancou R, Bertoglio J and Gacon G: A hemopoietic specific gene encoding a small GTP binding protein is overexpressed during T cell activation. Biochem Biophys Res Commun 175: 451-458, 1991.

18. Gu Y, Filippi MD, Cancelas JA, Siefring JE, Williams EP, Jasti AC, Harris CE, Lee AW, Prabhakar R, Atkinson SJ, et al: Hematopoietic cell regulation by Rac1 and Rac2 guanosine triphosphatases. Science 302: 445-449, 2003.

19. Joshi S, Singh AR, Zulcic M, Bao L, Messer K, Ideker T, Dutkowski J and Durden DL: Rac2 controls tumor growth, metastasis and M1-M2 macrophage differentiation in vivo. PLoS One 9: e95893, 2014. 
20. Roberts AW, Kim C, Zhen L, Lowe JB, Kapur R, Petryniak B, Spaetti A, Pollock JD, Borneo JB, Bradford GB, et al: Deficiency of the hematopoietic cell-specific Rho family GTPase Rac2 is characterized by abnormalities in neutrophil function and host defense. Immunity 10: 183-196, 1999.

21. Yang FC, Kapur R, King AJ, Tao W, Kim C, Borneo J, Breese R, Marshall M, Dinauer MC and Williams DA: Rac2 stimulates Akt activation affecting $\mathrm{BAD} / \mathrm{Bcl}-\mathrm{XL}$ expression while mediating survival and actin function in primary mast cells. Immunity 12 : $557-568,2000$

22. Cho YJ, Cunnick JM, Yi SJ, Kaartinen V, Groffen J and Heisterkamp N: Abr and Bcr, two homologous Rac GTPase-activating proteins, control multiple cellular functions of murine macrophages. Mol Cell Biol 27: 899-911, 2007.

23. Chuang TH, Xu X, Kaartinen V, Heisterkamp N, Groffen J and Bokoch GM: Abr and Bcr are multifunctional regulators of the Rho GTP-binding protein family. Proc Natl Acad Sci USA 92: 10282-10286, 1995.
24. Bax B: Domains of rasGAP and rhoGAP are related. Nature 392: 447-448, 1998

25. Scheffzek K, Ahmadian MR, Kabsch W, Wiesmüller L, Lautwein A, Schmitz F and Wittinghofer A: The Ras-RasGAP complex: Structural basis for GTPase activation and its loss in oncogenic Ras mutants. Science 277: 333-338, 1997.

26. Cherfils J and Zeghouf M: Regulation of small GTPases by GEFs, GAPs, and GDIs. Physiol Rev 93: 269-309, 2013.

27. Didsbury J, Weber RF, Bokoch GM, Evans T and Snyderman R rac, a novel ras-related family of proteins that are botulinum toxin substrates. J Biol Chem 264: 16378-16382, 1989.

28. Thomas EK, Cancelas JA, Chae HD, Cox AD, Keller PJ, Perrotti D, Neviani P, Druker BJ, Setchell KDR, Zheng Y, et al: Rac guanosine triphosphatases represent integrating molecular therapeutic targets for BCR-ABL-induced myeloproliferative disease. Cancer Cell 12: 467-478, 2007. 